\title{
A MOROSIDADE NO SECTOR LOCAL ESPAÑOL: FACTORES DE RISCO E PREVENCIÓN
}

Jorge OLMO

Isabel BRUSCA

Margarita LABRADOR

Resumo. A creación do Fondo para o Financiamento do Plan de Pagamento a Provedores (2012-2013) e o control fiscal dos períodos de pagamento son dúas medidas que pretenden reducir a morosidade pública. Neste contexto, o obxectivo do traballo é avaliar as medidas anteriores e comprobar se as características políticas e a contorna económica inflúen nos períodos de pagamento dos concellos españois. Para iso, realízase unha análise exploratoria e aplícase a metodoloxía de datos de panel (2009-2014). Contribúese en probar a eficiencia das políticas que combaten a morosidade e en analizar a liquidez municipal.

Palabras chave: Liquidez, Entidades Locais, Políticas Públicas, Condición financeira, Datos de Panel.

JEL: H60; H72; H81

Title: The delay in payments by the Spanish Local Authorities: Risk factors and prevention Abstract. The creation of the Supplier Payment Plan (2012-2013) and the introduction of a tax rule that allows to control the average payment periods are two policies aiming to reduce late payments by public authorities. In this context, the aim of this paper is to check the effectiveness of both policies and examine the influence of the political features and economic environment over the period of payment of Spanish municipalities. In order to achieve this goal, it carries out an exploratory analysis and panel data techniques (20092014) are applied. The main contribution is to prove the effectiveness of public policies avoiding late payments as well as to review the short-term financial position in municipalities.

Key words: Cash position, Local Governments, Public Policies, Political Factors, Financial Condition, Panel Data.

\section{Introdución}

Nos derradeiros anos véñense levando a cabo unha serie de reformas que teñen presente 0 espírito que impera no Pacto de Estabilidade e Crecemento da Unión Europea e no Tratado de Estabilidade, Coordinación e Gobernanza da Unión Económica e Monetaria do 2 de marzo de 2012. En concreto, en España en abril de 2012 publícase a Lei Orgánica 2/ 2012 de Estabilidade Orzamentaria e Sustentabilidade Financeira, co obxectivo de mellorar os controis de déficit, débeda e gasto público. Posteriormente, no ano 2013 mediante a Lei Orgánica 9/ 2013 do Control da débeda comercial do sector público modifícase a normativa de estabilidade orzamentaria, coa intención de introducir o principio de sustentabilidade da débeda comercial e deste xeito controlar os períodos de pagamento das administracións públicas. Neste senso, a débeda comercial enténdese como a morosidade da débeda pública cos provedores (Ramos, 2014). Esto implica que dende 2014 o período medio de pagamento das administracións públicas españolas configúrase como un novo referente de disciplina orzamentaria, daí que o incumprimento dos prazos de pagamento por parte das entidades locais convértese nun indicador inequívoco da situación financeira das mesmas (Saura, 2013).

Anteriormente e debido á gran cantidade de facturas pendentes que teñen as entidades locais españolas, constitúese o Fondo para o Financiamento do Plan de Pagamento a Provedores (FFPP) ${ }^{1}$, mecanismo de financiamento que dota cunha importante inxección de

10 marco legal da primeira fase do Plan de Pagamento a Provedores está regulado no Real Decreto 4/ 2012 polo que se determinan as obrigas de información e procedementos necesarios para establecer 
liquidez ás administracións públicas coa intención de liquidar parte da débeda comercial. A cantidade total aboada aos 123.733 provedores das entidades locais é de 11.595,47 millóns de euros, onde destaca sobre todo a primeira fase que financia un total de 9.598,34 millóns de euros (Ministerio de Facenda e Administracións Públicas, 2014).

Perante este contexto, o obxectivo del traballo consiste en estudar o efecto que ten o principio de sustentabilidade da débeda comercial nos períodos medio de pago, aspecto relacionado co marco teórico do federalismo fiscal, no que investigacións previas analizan a eficacia das limitacións das normas fiscais (Kiewiet e Szakaly, 1996). Adicionalmente, tamén se estuda a idoneidade do FFPP, para constatar se nesa política participaron os concellos con maiores atrasos no pagamento. Tamén se analiza a influencia que ten a contorna política na situación financeira a curto prazo do sector público local. A repercusión das características políticas na situación financeira nacional ou de diferentes rexións foi obxecto de numerosos artigos (Borge, 1995; Guillamón, 2011). En último lugar, tamén se pretende relacionar a situación económica das rexións locais españolas coa situación económica a curto prazo. Primeiro, introdúcense os ingresos correntes por habitante, variable que está relacionada coa capacidade económica da rexión. Despois, analízase se o nivel de investimento está relacionado co período medio de pagamento dos concellos españois.

Para contrastar estas cuestións, realízase unha análise exploratoria e, posteriormente, unha aplicación empírica mediante a metodoloxía de datos de panel.

A continuación, no seguinte apartado faise referencia á literatura previa e formúlanse as hipóteses que se desexan contrastar. Na terceira sección, defínese a metodoloxía utilizada na parte empírica. O cuarto apartado adícase á análise e discusión dos resultados obtidos. Por último, inclúense as conclusións finais.

\section{Literatura previa e formulación das hipóteses}

A formulación das hipótese divídese en tres apartados que están relacionados con: a influencia que teñen as políticas de disciplina de pagamento nas administracións locais españolas, as características políticas das entidades locais e da contorna económica local.

2.1. Influencia que teñen as reformas e as políticas públicas no período de pagamento

O marco teórico do federalismo fiscal trata de probar a eficacia que teñen os mecanismos legais en restrinxir e controlar mellor o endebedamento (Kiewiet e Szakaly, 1996; Vallés et al., 2003). Perante a inclusión dun novo mecanismo de control, exponse unha primeira hipótese que pretende comprobar o efecto que ten a normativa de control da débeda comercial. Coa publicación desta norma introdúcese un novo mecanismo de disciplina orzamentaria que trata de controlar e limitar a un prazo máximo de 30 días o período medio de pagamento a provedores das administracións públicas.

Para comprobar o impacto desta medida, inclúese un dummy temporal que diferencia o ano 2014 coa finalidade de analizar o impacto que ten o principio de sustentabilidade de débeda comercial no seu primeiro ano de vixencia. Neste caso espérase que o principio de sustentabilidade de débeda comercial nas entidades locais españolas fora eficaz (Kiewiet e Szakaly, 1996; García-Sánchez et al., 2011) e que o mesmo favoreza o control dos períodos de pagamentos:

un mecanismo de financiamento para o pagamento aos provedores das entidades locais e no Real Decreto 7/ 2012 polo que se crea o Fondo para o financiamento dos pagamentos a provedores.

A segunda fase está abeirada no Real Decreto 4/2013 de medidas de apoio ao emprendedor e de acicate do crecemento e da creación de emprego.

A terceira fase está regulada no Real Decreto 8/ 2013 de medidas urxentes contra a morosidade das administracións públicas e de apoio ás entidades locais con problemas financeiros. 
H1: O principio de sustentabilidade da débeda comercial limita o período de pagamento dos concellos, polo que en 2014 o período de pagamento se reducirá.

De maneira previa no ano 2012, como consecuencia da débeda comercial acumulada que teñen as administracións públicas, créase o FFPP. A necesidade deste Fondo radica en que as obrigas pendentes de pagamento do sector público no ano 2011 acadaran o 8\% del PIB, do cal o 2,1\% do PIB das débedas pendentes de pagamento pertencía ás entidades locais (Delgado-Tellez et al., 2015). É importante apuntar que gran cantidad das facturas foron aboadas a autónomos e empresas familiares, cuestión importante xa que en España as empresas familiares xeran un 65\% e 70\% do PIB e o 75\% do emprego (Charlo et al., 2016). Neste aspecto, se o FFPP pretende financiar a aqueles concellos que están en peor situación financeira, cabe esperar que as entidades locais que se acollen ao FFPP, tiñan maiores problemas de liquidez. En concreto, pódese entender que nos dous anos anteriores á participación no FFPP, os concellos que necesitan da inxección de liquidez presentan períodos de pagamento superiores.

H2- Os concellos que se acollen ao FFPP presentan períodos de pagamento máis elevados durante os dous anos previos á participación.

2.2. Influencia das características políticas do concello no período de pagamento

A literatura tamén analiza a influencia da ideoloxía na situación financeira local. Neste aspecto, Cusack (1997) define esta orientación coa manifestación de que "o partido político importa", referíndose en concreto ás políticas de gasto máis elevadas dos gobernos progresistas. A maioría dos traballos parten da hipótese de que os gobernos de tendencia progresista tenden a favorecer o gasto público ou o nivel de débeda, namentres que os partidos conservadores executan políticas públicas máis aforradoras (Kiewiet e Szalaky 1996). Porén, os resultados previos non permiten concluír con este debate xa que hai investigacións que non atopan unha relación significativa (Abizadeh e Gray, 1993), como ocorre en traballos que se circunscriben ao eido territorial español (Bastida e Benito, 2005; Guillamón et al., 2011).

A presente hipótese oriéntase conforme á formulación de Cusack (1997) de que o partido político importa, malia que neste caso os partidos progresistas en vez de ter máis débeda financeira, enténdese que acumulan máis débeda comercial, polo que os concellos con alcaldes progresistas atrásanse máis no pagamento das facturas cos provedores, por iso $\mathrm{H} 3$ formúlase do seguinte xeito:

- H3: Os concellos con alcaldes progresistas terán maior probabilidade de se atrasaren nos pagamentos cos seus provedores.

Tamén se analiza se o nivel de concentración ou fragmentación política inflúe nas finanzas locais. Neste senso, faise referencia á "hipótese Roubini e Sachs do goberno feble" (RSH) que significa que maior fragmentación deriva en máis gasto público, en déficits elevados e en máis débeda (Roubini e Sachs, 1989). Borge (1995) constata que o crecemento de gasto se reduce nos gobernos máis fortes, xa que estes pódense negar ás demandas dos grupos minoritarios. Pola contra, o caso das entidades locais españolas é diferente, xa que os gobernos con maior fragmentación política recorren a un menor gasto (Bastida et al., 2009) e acumulan menos débeda (Guillamón et al., 2011; Pérez-López et al., 2013; Vicente et al., 2013).

Neste caso H4 formúlase conforme ás conclusións das investigacións españolas, que reflicten que os gobernos locais máis fragmentados ou formados en coalicións, dende o punto de vista financeiro, se xestionan dun xeito máis prudente (Guillamón et al., 2011; Vicente et al., 2013):

- H4: Os concellos gobernados baixo coalicións políticas presentarán menores atrasos nos pagamentos. 
Con respecto á presenza de partidos locais ou rexionais no goberno municipal, Benito e Bastida (2008) atopan que os partidos políticos locais teñen unha pequena influencia nos niveis de impostos, fixando estes partidos tributos máis baixos, namentres que a súa presenza non afecta ao gasto nin ao resultado orzamentario. Pola contra, noutra investigación de Bastida et al. (2013) queda de manifesto que os partidos locais teñen unha relación positiva nos niveis de gasto, malia que o nivel de significancia é baixo.

Conforme ás investigacións previas que miden o grao de influencia dos partidos rexionais na situación financeira local, dedúcese que se os gobernos con representación rexional establecen tributos máis baixos e efectúan un maior gasto, posiblemente demórense máis no pagamento das facturas comerciais, por estas razóns H5 formúlase do seguinte xeito:

- H5: A presenza de partidos locais ou rexionais no goberno municipal incrementará os períodos de pagamento.

2.3 - Influencia da contorna económica local no período de pagamento

Por outra banda, os ingresos correntes son o principal recurso das entidades públicas, proba diso é que a contía media dos ingresos correntes pode superar o $75 \%$ da recadación en termos medios (Rodríguez et al., 2014). Navarro-Galera et al. (2016) obteñen que os ingresos correntes per cápita inflúen positivamente na sustentabilidade financeira dos concellos españois.

Enténdese que se a liquidación dos ingresos correntes por habitante resulta elevada, os concellos aboan as súas facturas cunha maior presteza, polo que a formulación de H6 se realiza do seguinte xeito:

- H6: Unha maior contía de ingresos correntes liquidados reducirá o período medio de pagamento dos concellos.

Tamén é importante analizar o esforzo de investimento. $O$ investimento debe respectar 0 principio de solidariedade interxeneracional, cuxo obxectivo é garantir ás xeracións futuras un nivel de vida axeitado sen trasladar unha carga financeira excesiva. Deste xeito, o investimento amósase como un dos factores determinantes do endebedamento, permitindo repercutir parte do custo dos proxectos de capital ás xeracións vindeiras (Vallés et al., 2003). Investigacións previas contrastan que o investimento ten unha relación positiva e significativa co endebedamento (Bastida e Benito, 2005; Pérez-López et al., 2014). Neste caso cabe agardar que canto máis elevados sexan os gastos de capital por habitante das entidades locais, maior é o período de pagamento, polo tanto $\mathrm{H7}$ formúlase na seguinte dirección:

- H7: A realización de maior investimento local implicará maiores atrasos no pagamento das débedas cos provedores.

\section{Deseño da investigación}

\subsection{Mostra escollida e definición de variables}

Para realizar a análise empírica pártese dunha mostra inicial que considera os concellos españois de máis de 20.000 habitantes, en total 396 concellos (Ministerio de Facenda e Función Pública, 2016b). O estudo céntrase nos concellos con máis poboación, por iso, tómase como referencia a cifra de 20.000 habitantes conforme ao nivel mínimo de prestación de servizos públicos que se establece no artigo 26 da Lei 7/ 1985 reguladora das Bases do Rexime Local. Traballos previos teñen como referencia esta clasificación cando seleccionan unha mostra superior a 50.000 habitantes (Navarro-Galera et al., 2016) ou utilizan unha mostra de concellos con población superior a 20.000 habitantes (Cabaleiro-Casal e BuchGómez, 2015). Cabe mencionar que se exclúen os concellos dos que non se dispón dalgún dato que é necesario para abordar esta investigación, polo que a mostra final é de 364 ( $91,67 \%$ dos concellos con población superior a 20.000 habitantes). En relación ao horizonte temporal que se analiza comprende o período 2009-2014. 
Táboa 1. Información das variables utilizadas ${ }^{2}$

\begin{tabular}{|c|c|c|c|c|}
\hline Variable & Cálculo & Sigla & Fonte & $\begin{array}{l}\text { Hipótese } \\
\text { № Senso }\end{array}$ \\
\hline $\begin{array}{l}\text { período medio } \\
\text { de pagamento }\end{array}$ & $\begin{array}{l}\text { (Obrigas pendentes } \\
\text { pagamento cap. II e VI / } \\
\text { Obrigas recoñecidas netas cap. II } \\
\text { e VI) } * 365\end{array}$ & PMP & $\begin{array}{l}\text { Aportados por } \\
\text { SIELOCAL (2016) }\end{array}$ & --- \\
\hline $\begin{array}{l}\text { Principio de } \\
\text { sustentabilidade } \\
\text { da débeda } \\
\text { comercial }\end{array}$ & $\begin{array}{l}\text { Variable que analiza a eficacia do } \\
\text { límite: } \\
\qquad \begin{array}{l}0 \rightarrow \text { De } 2009 \text { a } 2013 \\
1 \rightarrow 2014\end{array}\end{array}$ & lim_pmp & - & HI - \\
\hline $\begin{array}{l}\text { Participación no } \\
\text { FFPP }\end{array}$ & $\begin{array}{l}\text { Concellos que se acollen ao } \\
\text { FFPP: } \\
\text { - Toma o valor } 1 \text { nos dous } \\
\text { anos previos á } \\
\text { participación. } \\
\text { - O resto de anos toma o } \\
\text { valor } 0 \text {. } \\
\text { Concellos que non participan } \\
\text { FFPP: } \\
\text { - Toma o valor } 0 .\end{array}$ & plan_pago & $\begin{array}{l}\text { Web do Ministerio } \\
\text { de Facenda e } \\
\text { Función Pública } \\
\text { (2016a) }\end{array}$ & $H 2+$ \\
\hline $\begin{array}{l}\text { Ideoloxía } \\
\text { política }\end{array}$ & $\begin{array}{l}\text { Ideoloxía política do partido } \\
\text { político do alcalde que ten a } \\
\text { encomenda de goberno: } \\
\quad 0 \rightarrow \text { Conservador } \\
\quad 1 \rightarrow \text { Progresista }\end{array}$ & ideolog & $\begin{array}{c}\text { Web da } \\
\text { Secretaría de Estado } \\
\text { das Adminis- } \\
\text { tracións Públicas } \\
(2016)\end{array}$ & $H 3+$ \\
\hline $\begin{array}{l}\text { Gobernos en } \\
\text { maioría absoluta } \\
\text { ou minoría }\end{array}$ & $\begin{array}{l}\text { Hai maioría absoluta cando a } \\
\text { metade máis un dos concelleiros } \\
\text { pertencen ao mesmo partido } \\
\text { político: } \\
\quad 0 \rightarrow \text { Coalicións } \\
\quad 1 \rightarrow \text { Maioría absoluta }\end{array}$ & mayab_coal & $\begin{array}{c}\text { Web do } \\
\text { Ministerio de } \\
\text { Interior } \\
(2016)\end{array}$ & $H 4+$ \\
\hline $\begin{array}{c}\text { Presenza de } \\
\text { partidos locais }\end{array}$ & $\begin{array}{l}\text { Hai representación dun partido } \\
\text { local, se goberna o partido local } \\
\text { ou forma parte da coalición: } \\
\quad 0 \rightarrow \text { Non hai presenza } \\
\quad 1 \rightarrow \text { Presenza local }\end{array}$ & presenc_loc & $\begin{array}{l}\text { Web do } \\
\text { Ministerio de } \\
\text { Interior } \\
(2016)\end{array}$ & $H 5+$ \\
\hline $\begin{array}{l}\text { Recadación de } \\
\text { ingresos } \\
\text { correntes }\end{array}$ & $\begin{array}{l}\text { (Dereitos liquidados do cap. I ao } \\
\text { cap. V) / poboación }\end{array}$ & ing_cor_pc & $\begin{array}{l}\text { Web do Ministerio } \\
\text { de Facenda e } \\
\text { Función Pública } \\
\text { (2016b) }\end{array}$ & H6 - \\
\hline Investimento & $\begin{array}{l}\text { (Obrigas recoñecidas netas do } \\
\text { cap. VI e cap. VII) / poboación }\end{array}$ & inv_pc & $\begin{array}{l}\text { Web do Ministerio } \\
\text { de Facenda e } \\
\text { Función Pública } \\
\text { (2016b) }\end{array}$ & $H 7+$ \\
\hline
\end{tabular}

2 O cálculo dos indicadores realízase cos capítulos da clasificación económica de gastos e ingresos. Para o período medio de pagamento inclúense as obrigas recoñecidas e pendentes de pagamento en bens correntes e servizos (cap. II) e os investimentos reais (cap. VI). Para os ingresos correntes realízase a suma dos impostos directos (cap. I), impostos indirectos (cap. II), taxas e ingresos (cap. III), transferencias correntes (cap. IV) e ingresos patrimoniais (cap. V). O nivel de investimento calcúlase coa adición das obrigas recoñecidas netas en investimentos reais (cap. VI) e as transferencias de capital (cap. VII). 
Con respecto á variable objeto de estudo, utilízase o período medio de pagamento establecido na antiga Orde/4041/2004 que aproba a Instrución do modelo normal de Contabilidade Local, información que é proporcionada por SIELOCAL (2016). Na Táboa 1 defínense as variables que se utilizan e as observacións máis importantes.

\subsection{Metodoloxía}

Primeiro, realízase unha análise exploratoria que consiste en comprobar se os concellos que participan no FFPP son aqueles que presentan maiores atrasos no pagamento das súas obrigas. Despois, analízase a evolución do prazo medio de pagamento ao longo do período 2009-2014, horizonte temporal que se circunscribe coa introdución das medidas que pretenden reducir a morosidade das administracións públicas. Por outra banda, antes de realizar o contraste de hipóteses efectúase un test de diferenza de medias que permite comprobar se existen diferenzas significativas no período de pagamento para cada unha das variables políticas.

Posteriormente, para dar resposta ás hipóteses recórrese á metodoloxía de datos de panel. Arellano e Bover (1990) destacan algunhas vantaxes dos datos de panel con respecto ás series temporais ou aos datos de corte transversal: evitan problemas de agregación, maior facilidade no seguemento individual e permiten estimar modelos que teñen en conta diferenzas permanentes entre os individuos, malia que estas non se observen. Neste caso, o conxunto total de observacións forma un panel de datos balanzados.

Neste estudo trabállase con modelos estáticos de datos de panel (Bastida e Benito, 2005; Pérez-López et al., 2014). De antemá omítese a formulación do modelo pool xa que a regresión agrupada toma a información como un todo sen discriminar os datos temporais ou transversais (Pérez-López et al., 2013). Polo tanto, formúlase un modelo de efectos fixos (fixed effect - FE) que parte de que existen diferenzas constantes entre individuos e asume que existe un factor explicativo non observable na ecuación, que incide na variable explicada. Posteriormente, o test de Hausman permite seleccionar entre o modelo de efectos fixos (FE) con respecto ao modelo de efectos aleatorios (random effect - $\mathrm{RE}$ ). Como consecuencia, a forma funcional que é capaz de explicar e ver a relación das hipóteses co período medio de pagamento correspóndese coa seguinte fórmula:

$$
\begin{aligned}
\text { PMP }_{i t}=\beta_{0} & +\beta_{1} \text { lim_pmp } \\
& +\beta_{2} \text { plan_pago }_{i t}+\beta_{3} \text { ideolg }_{i t}+\beta_{4} \text { mayab_coal }_{i t} \\
& +\beta_{5} \text { presencloc } c_{i t}+\beta_{6} \text { ing_cor_p } c_{i t}+\beta_{7} \text { inv } p c_{i t}+\alpha_{i}+\varepsilon_{i t}
\end{aligned}
$$

Onde: i significa o concello que se analiza; t é o ano; $\alpha_{\mathrm{i}}$ sería o termo inobservable que recolle diferenzas entre individuos (no modelo FE é unha constante diferente para cada individuo, que é constante ao longo do tempo, e no modelo de RE é unha variable aleatoria), ? ${ }_{\text {it }}$ recollería os residuos.

\section{Discusión dos resultados}

4.1. Análise exploratoria da situación de liquidez municipal tendo presente as medidas aplicadas e a contorna política

Primeiro, deséxase comprobar se existen diferenzas entre os períodos medios de pagamento das entidades locais que participan no FFPP, con respecto ás que non se suscriben ao FFPP. Na Táboa 2 vese que nos tres escenarios contemplados, o prazo medio de pagamento dos concellos que participan nesta política é superior ao dos concellos que non reciben o financiamento. 
Táboa 2. Período medio de pagamento en días conforme á participación ou non no FFPP

\begin{tabular}{|c|c|c|c|c|c|c|c|c|}
\hline & & $\mathrm{N}$ & 2009 & 2010 & 2011 & 2012 & 2013 & 2014 \\
\hline \multirow{2}{*}{$\begin{array}{c}\text { Fase } 1 \\
\text { do } \\
\text { FFPP }\end{array}$} & $\begin{array}{l}\text { Concellos que participan no } \\
\text { FFPP en } 2012\end{array}$ & 261 & 111,98 & 130,90 & 153,10 & 106,72 & 88,67 & 83,23 \\
\hline & $\begin{array}{l}\text { Concellos que non participan } \\
\text { no FFPP en } 2012\end{array}$ & 103 & 70,37 & 72,33 & 73,79 & 80,40 & 68,35 & 62,54 \\
\hline \multirow{2}{*}{$\begin{array}{c}\text { Fase } 2 \\
\text { e } 3 d o \\
\text { FFPP }\end{array}$} & $\begin{array}{l}\text { Concellos que participan no } \\
\text { FFPP en } 2013\end{array}$ & 5 & 162,40 & 160,00 & 172,80 & 154,80 & 108,80 & 113,60 \\
\hline & $\begin{array}{l}\text { Concellos que non participan } \\
\text { no FFPP en } 2013\end{array}$ & 359 & 99,34 & 113,69 & 130,07 & 98,50 & 82,56 & 76,87 \\
\hline \multirow{2}{*}{$\begin{array}{c}\text { Fase 1, } \\
2 \text { e } 3 \\
\text { do } \\
\text { FFPP }\end{array}$} & $\begin{array}{l}\text { Concellos que participan no } \\
\text { FFPP en } 2012 \text { e } 2013\end{array}$ & 266 & 112,93 & 131,45 & 153,47 & 107,62 & 89,05 & 83,80 \\
\hline & $\begin{array}{l}\text { Concellos que non participan } \\
\text { no FFPP }\end{array}$ & 98 & 65,67 & 67,86 & 68,73 & 76,00 & 66,29 & 59,94 \\
\hline
\end{tabular}

Hai que indicar o grande acubillo que ten esta medida, xa que participan o $73 \%$ dos concellos da mostra, a meirande parte deles na primeira fase $(71,7 \%)$. Se se toma como referencia 0 momento de antes e despois da inxección de liquidez, constátase unha redución aproximada de 50 días no prazo de pagamento dos concellos que solicitan o financiamento. Polo tanto, compróbase que participan os concellos con maiores atrasos no período medio de pagamento e que permite reducir considerablemente os períodos de pagamento dos concellos.

Cun enfoque diferente ao anterior, o Gráfico 1 reflicte a evolución do período medio de pagamento dos 364 concellos españois de máis de 20.000 habitantes da mostra. Destácase unha importante redución dos prazos de pagamento a partir de 2011. Ao longo de 2012 rexístrase un descenso considerable do período medio de pagamento (en 30 días) debido fundamentalmente á inxección de liquidez da primeira fase do FFPP. En 2013 tamén se reduce o prazo de pago, período que coincide coa segunda e terceira fase FFPP. Despois, logo de incorporar en decembro de 2013 o principio de sustentabilidade da débeda comercial e a posterior publicación dos períodos medios de pagamento por parte das administracións públicas, aprecíase a incidencia que ten este novo mecanismo de disciplina orzamentaria na redución dos períodos de pagamento do exercicio 2014.

Gráfico 1. Evolución media do período de pagamento

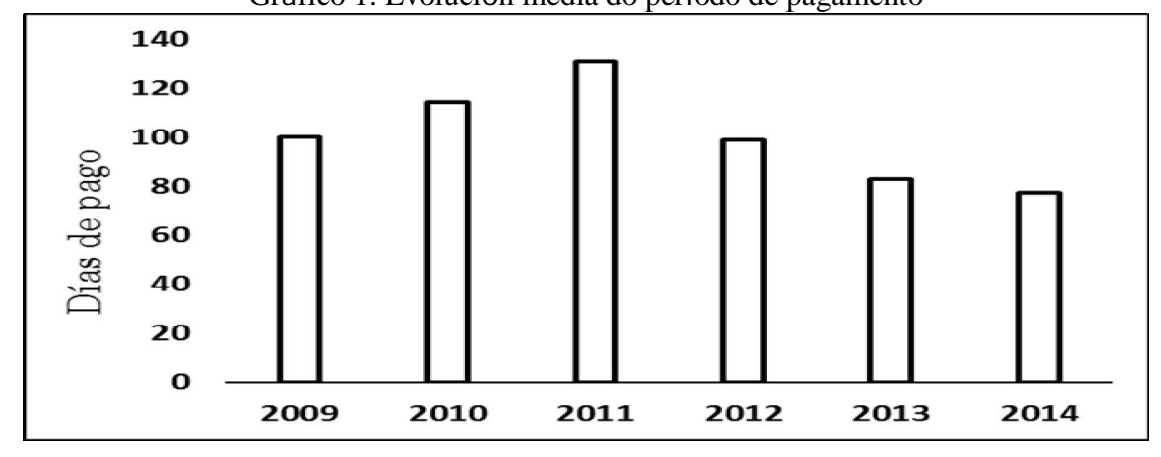


Por último, antes de responder ás hipóteses, realízase un test de diferenza de medias para as variables políticas (Táboa 3). Nesta proba ponse de manifesto a semellanza dos prazos de pagamento se se atende á ideoloxía política e á formación do goberno (arrededor de 100 días). Pola contra, aparecen diferenzas significativas de medias naqueles concellos nos que hai presenza de partidos locais no goberno, pagando estes as súas facturas 10 días máis tarde cós concellos que teñen un goberno representado por partidos de eido estatal (104, 98 días e 95,03 días).

Táboa 3. Test de diferenza de medias do período de pagamento conforme ás características políticas

\begin{tabular}{|c|c|c|c|c|c|c|c|}
\hline & & Obs & Media & Desviación & Diferenza & $\mathrm{t}$ & Sign \\
\hline \multirow{2}{*}{$\begin{array}{l}\text { Ideoloxía } \\
\text { política }\end{array}$} & Conservador & 1334 & 100,949 & 58,15 & \multirow{2}{*}{0,4027} & \multirow{2}{*}{0,16} & \multirow{2}{*}{0,8723} \\
\hline & Progresista & 850 & 100,547 & 55,31 & & & \\
\hline \multirow{2}{*}{$\begin{array}{l}\text { Fortaleza } \\
\text { do goberno }\end{array}$} & Coalición & 1090 & 99,938 & 53,87 & \multirow{2}{*}{$-1,705$} & \multirow{2}{*}{$-0,698$} & \multirow{2}{*}{0,4849} \\
\hline & Maioría absoluta & 1094 & 101,644 & 60,06 & & & \\
\hline \multirow{2}{*}{$\begin{array}{c}\text { Presenza } \\
\text { de partidos } \\
\text { locais }\end{array}$} & $\begin{array}{l}\text { Representación dalgún partido } \\
\text { local no goberno }\end{array}$ & 1264 & 104,983 & 59,77 & \multirow{2}{*}{9,947} & \multirow{2}{*}{4,037} & \multirow{2}{*}{0,0001} \\
\hline & $\begin{array}{l}\text { Non hai presenza de partidos } \\
\text { locais no goberno }\end{array}$ & 920 & 95,035 & 52,57 & & & \\
\hline
\end{tabular}

\subsection{Explicación do PMP coa metodoloxía de datos de panel}

Primeiro, para responder ás hipóteses, na configuración dos modelos óptase por separar dúas variables políticas: fortaleza do goberno e a variable que define se hai presenza dalgún partido local no goberno municipal, debido ao grao de correlación que existe entre elas (0.6729). Logo desta precisión, elabóranse os modelos de FE e RE coa intención de realizar o test de Hausman e deste xeito seleccionar o máis axeitado. Polo tanto, a través desta proba rexéitase a hipótese nula de igualdade das estimacións, polo que se selecciona o modelo de efectos fixos xa que proporciona os estimadores máis consistentes. Por este motivo, a Táboa 4 limítase a incluír os coeficientes e os estatísticos da estimación de FE e de estimación de FE robusta con corrección por heterocedasticidade. Tamén se recolle a significatividade conxunta dos modelos e o test de $\mathrm{F}$ que comproba que os efectos individuais son estatísticamente significativos. Ademais, aprecíase que a significatividade e signo que presentan cada unha das variables coincide nas catro estimacións e que a capacidade explicativa dos modelos da un $\mathrm{R}^{2}$ within do $23,71 \%$.

Con respecto aos resultados, destácase que a introdución do principio de sustentabilidade de débeda comercial como regra fiscal permitiu reducir o período de pagamento dos concellos españois durante o primeiro ano de vixencia. Deste xeito, ao presentar signo negativo a variable que estuda o efecto do límite dos prazos de pagamento, significa que no ano 2014 se rexistran períodos de pagamento máis reducidos. Como o control fiscal dos períodos de pagamento é un mecanismo recente, non existen traballos previos que comproben este instrumento de control, porén, no marco teórico do federalismo fiscal atópanse as investigacións que analizan a eficacia das limitacións do endebedamento. Kiewiet e Szakaly (1996) evidencia a eficacia de diferentes clases de límites para os distintos tipos de débeda americana. Este resultado coincide con traballos semellantes no eido español que proban a efectividade do límite legal de endebedamento que figura no TRLHL (Vallés et al., 2003, 
Cabasés et al., 2007). Porén, neste campo tamén hai resultados que non atopan un efecto significativo da normativa de estabilidade de 2001 (Brusca et al., 2015)

Táboa 4. Estimacións de efectos fixos que explican o período medio de pagamento

\begin{tabular}{|c|c|c|c|c|c|c|c|c|}
\hline \multirow{3}{*}{ Variables } & \multicolumn{4}{|c|}{$\begin{array}{l}\text { Estimación A - Analiza a influencia da } \\
\text { fortaleza política do goberno }\end{array}$} & \multicolumn{4}{|c|}{$\begin{array}{c}\text { Estimación B - Analiza a presenza de partidos } \\
\text { rexionais no goberno }\end{array}$} \\
\hline & \multicolumn{2}{|l|}{$\mathrm{FE}$} & \multicolumn{2}{|c|}{ FE ROBUST } & \multicolumn{2}{|l|}{$\mathrm{FE}$} & \multicolumn{2}{|c|}{ FE ROBUST } \\
\hline & Coef. & $\mathrm{t}$ & Coef. & $\mathrm{t}$ & Coef. & $\mathrm{t}$ & Coef. & $\mathrm{t}$ \\
\hline lim_pmp & $\begin{array}{c}- \\
16,007 * * *\end{array}$ & $-7,36$ & $-16,007 * * *$ & $-9,00$ & $-16,001 * * *$ & $-7,36$ & $-16,001 * * *$ & $-9,00$ \\
\hline plan_pago & $28,09 * * *$ & 14,64 & $28,09 * * *$ & 12,92 & $28,101 * * *$ & 14,64 & $28,101 * * *$ & 12,91 \\
\hline ideolog & $-3,461$ & $-1,27$ & $-3,461$ & $-0,99$ & $-3,3005$ & $-1,25$ & $-3,3005$ & $-0,98$ \\
\hline mayab_coal & $-0,725$ & $-0,27$ & $-0,725$ & $-0,23$ & -------------- & ------ & - & -------- \\
\hline presenc_loc & ------------ & ------ & ------------ & ------ & 0,4284 & 0,15 & 0,4284 & 0,12 \\
\hline ing_cor_pc & $-0,083 * * *$ & $-0,49$ & $-0,082 * * *$ & $-6,15$ & $\stackrel{-}{-} 0,082^{* * *}$ & $-7,87$ & $-0,082 * * *$ & $-6,16$ \\
\hline inv_pc & 0,0034 & 18,15 & 0,003 & 0,43 & 0,0033 & 0,47 & 0,0033 & 0,41 \\
\hline cons & $171,25 * * *$ & $-7,36$ & $171,25 * * *$ & 14,35 & $170,719 * * *$ & 18,11 & $170,71 * * *$ & 14,45 \\
\hline $\mathrm{R}^{2}$ _within & \multicolumn{2}{|c|}{$22,31 \%$} & \multicolumn{2}{|c|}{$22,31 \%$} & \multicolumn{2}{|c|}{$22,31 \%$} & \multicolumn{2}{|c|}{$22,31 \%$} \\
\hline $\begin{array}{l}\text { Significatividade } \\
\text { conxunta }\end{array}$ & \multicolumn{2}{|c|}{$\begin{array}{c}F=86,82 \\
\text { Prob }>F=0,000\end{array}$} & \multicolumn{2}{|c|}{$\begin{array}{c}F=55,63 \\
\text { Prob }>F=0,000\end{array}$} & \multicolumn{2}{|c|}{$\begin{array}{c}F=86,81 \\
\text { Prob }>F=0,000\end{array}$} & \multicolumn{2}{|c|}{$\begin{array}{c}F=56,05 \\
\text { Prob }>F=0,000\end{array}$} \\
\hline Test de F & \multicolumn{2}{|c|}{$\begin{array}{c}10,08 \\
\text { Prob }>\mathrm{F}=0,000\end{array}$} & & & \multicolumn{2}{|c|}{$\begin{array}{c}10,08 \\
\text { Prob }>F=0,000\end{array}$} & \multicolumn{2}{|l|}{-------- } \\
\hline Test de Hausman & \multicolumn{2}{|c|}{$\begin{array}{c}\mathrm{Chi}^{2}=205,36 \\
\text { Prob }>\mathrm{Chi}^{2}=0,000\end{array}$} & & & \multicolumn{2}{|c|}{$\begin{array}{c}\mathrm{Chi}^{2}=360,59 \\
\text { Prob }>\mathrm{Chi}^{2}=0,000\end{array}$} & & \\
\hline
\end{tabular}

En segundo lugar, constátase que a variable relacionada co FFPP ten signo positivo, o cal significa que os concellos que participan no FFPP teñen os prazos de pagamento máis elevados durante os dous anos previos á subscrición da medida. Isto amosa a aceptación e idoneidade do FFPP xa que se acollen os concellos que teñen máis débeda comercial acumulada. Os atrasos nos pagamentos son un indicio de dificuldades financeiras, xa que poden definir situacións de estrés fiscal, neste senso, vese que cidades que están en bancarrota caracterízanse por ter ocupado ránkings de liquidez máis baixos (Singla et al., 2014). Por outra banda, hai evidencia empírica dos efectos económicos beneficiosos que ten a inxección de liquidez do FFPP na redución do desemprego, tanto para os concellos que solicitan o financiamento, como para as empresas que reciben os fondos (Bermejo et al., 2015). 
Con respecto ás variables políticas, constátase que non existe influencia da contorna política na situación de morosidade das entidades locais españolas. Bastida e Benito et al. (2009) xustifican que o partido político non inflúe nos niveis de gasto ou ingresos xa que as políticas dos concellos españois están baseadas nas necesidades directas dos cidadáns, o cal implica que a ideoloxía política ten un menor impacto nas administracións máis achegadas á cidadanía. Tamén hai resultados que evidencian o pouco impacto que teñen os partidos locais na situación financeira dos concellos españois (Benito e Bastida, 2008), así como a non incidencia da formación do goberno (maioría absoluta ou coalición) no nivel de endebedamento (Pérez-López et al., 2014, Ribeiro e Jorge, 2014). Polo tanto, obtense que as características políticas das entidades locais non inflúen na situación financeira a curto prazo.

Tamén se evidencia a significatividade e signo negativo que presentan os ingresos correntes no período de pagamento, é dicir, os concellos que liquidan menos ingresos correntes teñen maiores atrasos nos pagamentos das débedas cos seus provedores. Polo tanto, o aumento dos ingresos correntes primarios ademais de ser unha estratexia que serve para poñer freo aos niveis de endebedamento (Vallés et al., 2003), tamén resultaría axeitado para reducir os períodos medios de pagamento. Ademais, obter maior volume de ingresos correntes na conta de resultados inflúe de maneira favorable na sustentabilidade financeira (Navarro-Galera et al., 2016) e como se amosou neste caso tamén inciden favorablemente na sustentabilidade da débeda comercial.

Por último, resulta interesante comprobar que o nivel de investimento non é unha variable con influencia estatísticamente significativa na situación de liquidez, a diferenza do que ocorre co endebedamento (Cabasés et al., 2007; Pérez-López et al., 2014), xa que a débeda xunto cos ingresos de capital deben de financiar investimentos para preservar o equilibrio orzamentario e respectar as premisas que establece o TRLHL (Bastida e Benito 2005). Polo tanto, este resultado non significativo pódese deber a que os empréstitos bancarios a longo prazo fan fronte ao gasto de capital e as posibles demoras dos concellos están máis relacionadas coa contía do gasto en bens correntes e servizos correntes.

\section{Conclusións}

O Fondo para o Financiamento do Plan de Pagamento a Provedores facilitou aos concellos a obtención de financiamento coa finalidade de saldar parte da débeda comercial. Como consecuencia, a meirande parte dos concellos españois necesitaron da inxección de liquidez para resolver as obrigas que tiñan cos provedores. Un aspecto fundamental que se deriva da participación neste mecanismo é que supuxo a reconversión da débeda comercial en débeda financeira.

Ademais, coa modificación da normativa de morosidade e a introdución do principio de sustentabilidade de débeda comercial en decembro de 2013, ponse de manifiesto que hai un maior interese por reducir a insolvencia do sector público e por controlar fiscalmente os prazos de pagamento.

Neste marco, este traballo contribúe empiricamente en probar o éxito das medidas que tiñan como obxectivo reducir a morosidade pública. Polo tanto, próbase que o criterio de sustentabilidade da débeda comercial permitiu reducir os períodos medios de pagamento dos concellos durante o seu primeiro ano de vixencia (2014). Tamén se constata que co Fondo para o Financiamento do Plan de Pagamento a Provedores reducíronse os períodos de pagamento dos concellos que participaron e que aqueles concellos que se acolleron ao mesmo eran os que maiores atrasos presentaban nos prazos de pagamento, polo tanto, pódese afirmar a aceptación e idoneidade da devandita política. 
Outra aportación realizada é a comprobación da irrelevancia que ten a contorna política na situación de liquidez dos concellos españois. Neste senso, afírmase que a ideoloxía política do alcalde, a fortaleza política ou a presenza de partidos rexionais no goberno non inflúen nos atrasos de pagamento das débedas comerciais. Pola contra, os ingresos correntes están relacionados coa situación financeira a curto prazo, namentres que o nivel de investimento non é unha variable explicativa.

Os resultados desta investigación son de grande utilidade práctica para a xestión pública, así como para o deseño e valoración de políticas orzamentarias para as rexións españolas. Neste suposto constátase a eficacia do principio de sustentabilidade de débeda comercial, malia que non se pode descartar que a efectividade deste límite tamén se vexa favorecida polo mesmo impulso do Fondo para o Financiamento do Plan de Pagamento a Provedores. Así mesmo, coñecer as áreas que afectan á situación financeira a curto prazo resulta indispensable para mellorar o control da liquidez por parte dos xestores dos concellos. Do mesmo xeito, o lexislador español ten un maior coñecemento na elaboración de normas adicionais que pretendan reforzar o límite de trinta días fixado para o período de pagamento, como por exemplo, incorporando referencias baseadas nos ingresos correntes como ocorre cos límites do nivel de endebedamento.

Este traballo non está exento de limitacións. Este estudo centrouse nos concellos de máis de 20.000 habitantes, polo que a situación de morosidade das pequenas localidades non se analizaron. Do mesmo xeito, tamén se podería considerar o estudo da morosidade considerando a información das Comunidades Autónomas ou rexións provinciais.

A análise da liquidez non remata co enfoque deste estudo e ábrense futuras liñas de investigación. Neste aspecto, proponse relacionar a contorna socioeconómica -densidade de poboación, desemprego, inmigración- das rexións españolas coa situación de liquidez e levar a cabo a formulación dun modelo dinámico de datos de panel.

\section{Bibliografía}

Abizadeh, S. y Gray, John A. (1993). Provincial Government Expenditures in Canada: An Empyrical Analysis. International Review of Applied Economics, 7 (1), 69-90. Disponible en: http:/ / dx.doi.org/ 10.1080/ 758528253.

Arellano, M. y Bover, O. (1990). La Econometría de Datos de Panel. Investigaciones económicas, 14 (1), pp. 3-45.

Bastida, F. J. y Benito, B. (2005). Análisis del endeudamiento en los Ayuntamientos: un Estudio Empírico. Revista Española de Financiación y Contabilidad, 34 (126), 613-635. Disponible en: http:/ / dx.doi.org/ 10.1080/ 02102412.2005.10779556.

Bastida, F. J., Benito, B. y Guillamón, M.D. (2009). An Empirical Assesment of the Municipal Financial Situation in Spain. International Public Management Journal, 12 (4), 489-499. Disponible en: http:/ / dx.doi.org/ 10.1080/10967490903328139.

Bastida, F. J., Guillamón, M.D. y Benito, B. (2013). Municipal Spending in Spain: Spatial Approach. Journal of Urban Planning and Development, 139 (2), 79-93. Disponible en: http:/ / dx.doi.org/ 10.1061/ (ASCE)UP.1943-5444.0000138.

Benito, B. y Bastida, F.J. (2008). Política y gestión financiera municipal. Revista de Contabilidad-Spanish Accounting Review, 11 (2), 43-66. Disponible en:

http:/ / www.rc-sar.es/ verPdf.php?articleId=178. 
Bermejo, V. J., Campos, R. G. y Abad, J. M. (2015). How does easing liquidity constraints affect aggregate employment?. UC3M Working papers, ISSN 2387-175X. Disponible en: http:// earchivo.uc3m.es/ handle/ 10016/22116.

Borge, L. (1995). Economic and political determinants of fee income in Norwegian Local Governments. Public Choice, 83 (3-4), 353-373.

Disponible en: http:/ / dx.doi.org/ 10.1007/ bf01047752.

Brusca, I., Labrador, M. y Montesinos, V. (2015). Influencia de las elecciones en la gestión de los gobiernos locales. Gestión y Política Pública, XXIV (2), 459-489.

Disponible en: http:/ / www .redalyc.org/ articulo.oa?id=13341044005.

Cabaleiro-Casal, R. y Buch-Gómez, E. J. (2015). Public Spending Policies and Budgetary Balances: Evidence from Spanish Municipalities. Lex Localis, 13 (4), 973-994. Disponible en: https:/ / doi.org/ 10.4335/ 13.3.973-994(2015).

Cabasés, F, Pascual, P. y Vallés, J. (2007). The effectiveness of institutional borrowing restrictions: empirical evidence from Spanish municipalities. Public Choice, 131 (3-4), 293313. Disponible en: http:/ / doi.org/ 10.1007/s11127-006-9116-y.

Charlo, M.J., Nuñez, M. y Sánchez-Apellániz, M. (2016). Perfil de la empresa familiar en España y Andalucía. Regional and Sectoral Economic Studies, 16 (2), 167-184.

Cusack, T. R. (1997). Partisan politics and public finance: Changes in public spending in the industrialized democracies, 1955-1989. Public Choice, 91 (3-4), 375-395. Disponible en: http:/ / doi.org/ 10.1023/ A:1004995814758.

Delgado-Téllez, M., Hernández de Cos, P., Hurtado, S. y Pérez J. J. (2015). Los mecanismos extraordinarios de pago a proveedores de las administraciones públicas en España. (Documentos Ocasionales, 1501, pp. 1-31). Madrid: Banco de España. Disponible en: http:/ / doi.org/ doi:10.2139/ssrn.2567257.

García-Sánchez, I. M., Prado-Lorenzo, J.M. y Cuadrado-Ballesteros, B. (2011). Do progressive goverments undertake different debt burdens? Partisan vs. Electoral Cycles. Revista de Contabilidad-Spanish Accounting Review, 14 (1), 29-57. Disponible en: https:/ / doi.org/ 10.1016/ S1138-4891(11)70021-8.

Guillamón, M.D., Benito, B. y Bastida, F.J. (2011). Evaluación de la deuda pública local en España. Revista Española de Financiación y Contabilidad, XL (150), 251-285. Disponible en: http:/ / dx.doi.org/ 10.1080/ 02102412.2011.10779703.

Kiewiet, D.R. y Szalaky, K. (1996). Constitutional limitations on borrowing: An analysis of state bonded indebtedness. Journal of Law, Economics and Organization, 12 (1), 62-97. Disponible en: https:/ / doi.org/ 10.1093/ oxfordjournals.jleo.a023362.

Ministerio de Hacienda y Administraciones Públicas (2014). Balance final del Fondo de Proveedores: 41.814 millones de euros para pagar más de ocho millones de facturas. Nota de Prensa de la Secretaria de Prensa del Ministerio de Hacienda y Administraciones Públicas.

Disponible en:

http:/ / www.minhafp.gob.es/ Documentacion/ Publico/ GabineteMinistro/ Notas\%20Prensa/ 2014/ S.\%20E.\%20ADMINISTRACIONES\%20P\%C3\%9ABLICAS/ 16-0714\%20Fondos\%20Proveedores.pdf.

Ministerio de Hacienda y Función Pública (2016a). Información de los planes de ajuste de las Entidades Locales. 10-01-2016. Disponible en: http://www.minhafp.gob.es/ es- 
ES/ Areas\%20Tematicas/Administracion\%20Electronica/ OVEELL/ Paginas/ PlanesdeAjusteE ntidadesLocales.aspx.

Ministerio de Hacienda y Función Pública (2016b). Liquidaciones de los presupuestos de entidades locales. 10-01-2016. Disponible en:

http:/ / serviciostelematicosext.minhap.gob.es/ SGCAL/ entidadeslocales/.

Ministerio del Interior (2016). Consulta de resultados electorales. 20-01-16. Disponible en: http:/ / www.infoelectoral.mir.es/ min/

Navarro-Galera, A., Rodríguez-Bolívar, M.P., Alcaide-Muñoz, L. y Deseada-López, M. (2016). Measuring the financial sustainability and its influential factors in local governments, Applied Economics, 48 (41), 3961- 3975.

Disponible en: http:/ / dx.doi.org/ 10.1080/ 00036846.2016.1148260.

Pérez-López, G., Plata-Díaz, A.M., Zafra-Gómez, J.L. y López-Hernández, A. M. (2013). Deuda viva municipal en un contexto de crisis económica: análisis de los factores determinantes y de las formas de gestión. Revista de Contabilidad-Spanish Accounting Review, 16 (2), 83-93.

Disponible en: http:/ / doi.org/ 10.1016/ j.rcsar.2012.12.001.

Pérez-López, G., Plata-Díaz, A.M., Zafra-Gómez, J.L. y López-Hernández, A. M. (2014). Operaciones fuera de presupuesto (off budget), factores políticos y deuda municipal. Gestión y Política Pública, 23 (1), 185-218. Disponible en:

http:/ / www .redalyc.org/ articulo.oa?id=13331169005.

Ramos, E. (2014). Las recientes novedades legislativas en el marco económico de las entidades locales. Presupuesto y Gasto Público, (77), 265-277. Disponible en:

http:/ / www.ief.es/documentos/ recursos/ publicaciones/revistas/presu gasto publico/ 771 4.pdf.

Ribeiro, N. y Jorge, S. (2014). Determinantes do endividamento da administração local: estudo exploratório nos municípios do norte Portugal. Revista Innovar Journal, 24 (51), 6178. Disponible en: https:// doi.org/ 10.15446/ innovar.v24n51.41488.

Rodríguez, M.P., Navarro, A., Alcaide, L. y López M.D. (2014). Factors Influencing Local Government Financial Sustainability: An Empirical Study. Lex Localis - Journal of Local SelfGovernment, 12 (1), 31-54. Disponible en: http:/ / doi.org/ 10.4335/ 12.1.31-54.

Roubini, N. y Sachs, J. (1989). Political and economic determinants of budget deficits in the industrial democracies. European Economic Review, 33 (5), 903-933. Disponible en: https:// doi.org/ 10.1016/ 0014-2921(89)90002-0.

Saura, J.J. (2013). Problemas prácticos (y algunas soluciones) para el endeudamiento local. Presupuesto y Gasto Público, (73), 179-195.

Secretaría de Estado de Administraciones Públicas (2016). Base de datos de Alcaldes. Elecciones 1979-2015. 20-01-16. Disponible en:

http:/ / www.seat.mpr.gob.es/ portal/areas/politica local/ sistema de informacion local -SILLdatos legislaturas 1979 2015.html.

Sielocal (2016). Periodo medio pago de los ayuntamientos. Datos proporcionados bajo petición. 6-05-2016. Dirección: http:// www.sielocal.com/.

Singla, A., Comeaux, J., Kirschner y Glenn, J. (2014). Blind, broke, and bedlam: Differentiating fiscal stress from bankruptcy in California. Public Finance and Management, 14 (3), 306-328. ISSN: 1523-9721. 
Vallés, J., Pascual, P. y Cabasés, F. (2003). Endeudamiento municipal y efectividad de las restricciones institucionales de disciplina crediticia (1988-2000). Hacienda Pública Española / Review of Public Economics, 166 (3), 9-47. Disponible en:

http:/ / www.ief.es/ documentos/ recursos/ publicaciones/ revistas/ hac pub/ 166 Valles.pdf.

Vicente, C., Ríos, A.M. y Guillamón, M.D. (2013). Voting behavior and budget stability. Revista de Contabilidad-Spanish Accounting Review, 16 (1), 46-52. Disponible en: https:/ / doi.org/ 10.1016/ S1138-4891(13)70005-0.

Revista Galega de Economía: http:/ / www.usc.es/ econo/ RGE/ benvidag.htm 